\title{
Structure Governs the Deformability of Polymer Particles in a Micro- fluidic Blood Capillary Model
}

\author{
Huanli Sun, ${ }^{\mathrm{a}, \mathrm{b}, \ddagger}$ Mattias Björnmalm, ${ }^{\mathrm{a}, \mathrm{b}, \ddagger}$ Jiwei Cui, ${ }^{\mathrm{a}, \mathrm{b}}$ Edgar H. H. Wong, ${ }^{\mathrm{b}}$ Yunlu Dai, ${ }^{\mathrm{a}, \mathrm{b}}$ Qiong \\ Dai, ${ }^{\mathrm{a}, \mathrm{b}}$ Greg G. Qiao, ${ }^{\mathrm{b}, *}$ and Frank Caruso ${ }^{\mathrm{a}, \mathrm{b}, *}$ \\ ${ }^{a}$ ARC Centre of Excellence in Convergent Bio-Nano Science and Technology, The University of Melbourne, \\ Parkville, Victoria 3010, Australia, and the ${ }^{\mathrm{b}}$ Department of Chemical and Biomolecular Engineering, The University \\ of Melbourne, Parkville, Victoria 3010, Australia.
}

\begin{abstract}
Particle stiffness is a design parameter that affects bio-nano interactions, such as biodistribution kinetics and cell processing. Herein, we develop soft polysaccharide (hyaluronic acid, HA) replica particles and capsules with tunable stiffness and sizes similar to human red blood cells (RBCs) via atom transfer radical polymerization-mediated continuous assembly of polymers $\left(\mathrm{CAP}_{\text {ATRP }}\right)$, and investigate their stiffness and deformability using colloidal-probe atomic force microscopy (CP-AFM) and a microfluidic blood capillary model. We demonstrate that HA replica particles and capsules with comparable nanoscale stiffness exhibit significantly different behaviors in a microfluidic blood capillary model. HA capsules behaved as RBCs while HA replica particles had difficulty passing through the capillaries. These results (i) demonstrate how flow-based deformability measurements can be used to complement nanoscale stiffness measurements and (ii) provide important insight into the role of particle structure on the flow-based deformability of soft replica particles and capsules in a physiologically relevant microfluidic model.
\end{abstract}

Engineered nanostructured particles are of interest due to their potential application in various fields, such as drug delivery, nanoreactors, sensors, and artificial organelles. ${ }^{1-5}$ The performance of engineered particles in biological environments is governed by their ability to negotiate biological barriers, ${ }^{6-8}$ which is determined by both the biological target environment and the physicochemical properties of the particles, including size, shape, surface chemistry, and stiffness. ${ }^{9-12}$

Stiffness and deformability are particle characteristics that have recently gained increasing interest, as they have been shown to strongly influence the cellular interaction and processing of engineered particles. ${ }^{13-17}$ An example of reversible deformability found in nature is that of human red blood cells (RBCs), which routinely and repeatedly deform to pass through blood capillaries smaller than themselves. ${ }^{18,19}$ Inspired by this, several types of particles with varying stiffnesses and shapes have been engineered and subjected to constricted channels to investigate their deformability. ${ }^{20-27}$ Soft particles with high deformability were found to deform to pass through constricted environments, a behavior that correlated with extended circulation times in vivo. ${ }^{28-30}$ Although these studies provide important insights into how particles of various materials can be engineered to have different mechanical properties and biological behavior, the effect of the internal structure of soft polymer particles on deformability behavior remains to be explored.
Herein, we use a recently developed templating technique, called continuous assembly of polymers (CAP), ${ }^{14,31-}$ 33 to engineer polymer capsules (i.e., with a hollow interior) and porous replica particles (i.e., with a structured interior) with tunable stiffness and similar size to RBCs, and investigate their deformability through liquid colloidal-probe atomic force microscopy (CP-AFM) $)^{34,35}$ and a microfluidic blood capillary model (Scheme 1 ). ${ }^{27}$ The replica particles and capsules were both made of hyaluronic acid (HA) and could be engineered with tunable stiffness, as assessed by CP-AFM. The flow-based deformability of the replica particles and capsules were then investigated using a microfluidic blood capillary model and, interestingly, a clear difference was observed between capsules and replica particles, even though both particle types had similar nanoscale stiffness. These results provide key insight into the importance of internal particle structure on the overall physical and mechanical properties and highlight how high-resolution CP-AFM results can be complemented by larger scale flow-based deformability measurements to facilitate the rational design of soft particles with enhanced performance in physiological environments.

To prepare HA capsules and replica particles, atom transfer radical polymerization-mediated CAP $\left(\mathrm{CAP}_{\text {ATRP }}\right)$ was used. HA, a natural polysaccharide, was chosen to construct the capsules and replica particles due to its high biocompatibility, non-immunogenicity and targeting abil- 
ity, which are important for any future biomedical applications. $^{36,37}$ HA capsules with similar size to RBCs were prepared via CAP $_{\text {ATRP }}$ of methacrylate-functionalized HA (HA-AEMA, see Scheme Sia in Supporting Information) on sacrificial $\mathrm{SiO}_{2}$ particles $(7.0 \mu \mathrm{m}$ in diameter) and subsequent template removal. The $\mathrm{CAP}_{\mathrm{ATRP}}$ step number was altered from 1 to 4 to afford $\mathrm{HA}$ capsules $\left(\mathrm{HA}_{\mathrm{C}_{1}}, \mathrm{HA}_{\mathrm{C}_{2}}\right.$, $\mathrm{HA}_{\mathrm{C}_{3}}$, and $\mathrm{HA}_{\mathrm{C}_{4}}$, respectively) with different wall thickness and stiffness, as reported previously. ${ }^{14}$ HA capsules were further labeled with an Alexa Fluor $488 \mathrm{~N}$ hydroxysuccinimide ester to enable fluorescence imaging. The capsules were imaged using fluorescence, differential interference contrast (DIC), and deconvolution microscopy, as well as transmission electron microscopy (TEM) and AFM (Figure 1 and Figure S1). The HA capsules were well dispersed in aqueous solution with a hollow structure and a diameter of $\sim 7 \mu \mathrm{m}$. All HA capsules $\left(\mathrm{HA}_{\mathrm{C}_{1}}-\right.$ $\mathrm{HA}_{\mathrm{C}_{4}}$ ) showed the collapsed structure with folds and creases in the air-dried state, as commonly observed for hollow capsules. ${ }^{38}$ In addition, AFM analysis of HA capsules showed a linear increase in capsule wall thickness from $\sim 4.5 \mathrm{~nm}\left(\mathrm{HA}_{\mathrm{C}_{1}}\right)$ to $\sim 15.9 \mathrm{~nm}\left(\mathrm{HA}_{\mathrm{C}_{4}}\right.$, Figure $\left.\mathrm{S}_{2}\right)$ with the number of $\mathrm{CAP}_{\text {ATRP }}$ steps, which is consistent with our previous study of HA film growth on $2.4 \mu \mathrm{m} \mathrm{SiO}{ }_{2}$ particles. $^{14}$

Scheme 1. Schematic illustration of CAP ATRP- $^{-}$ mediated formation of (a) HA hollow capsules using $\mathrm{SiO}_{2}$ templates and (b) HA replica particles using mesoporous silica (MS) templates, and (c) their deformability in a microfluidic blood capillary model. HA-coated $\mathrm{SiO}_{2}$ particles ( $\mathrm{SiO}_{2} @ \mathrm{HA}$ ) and RBCs were used as controls. Full experimental details are available in Supporting Information.

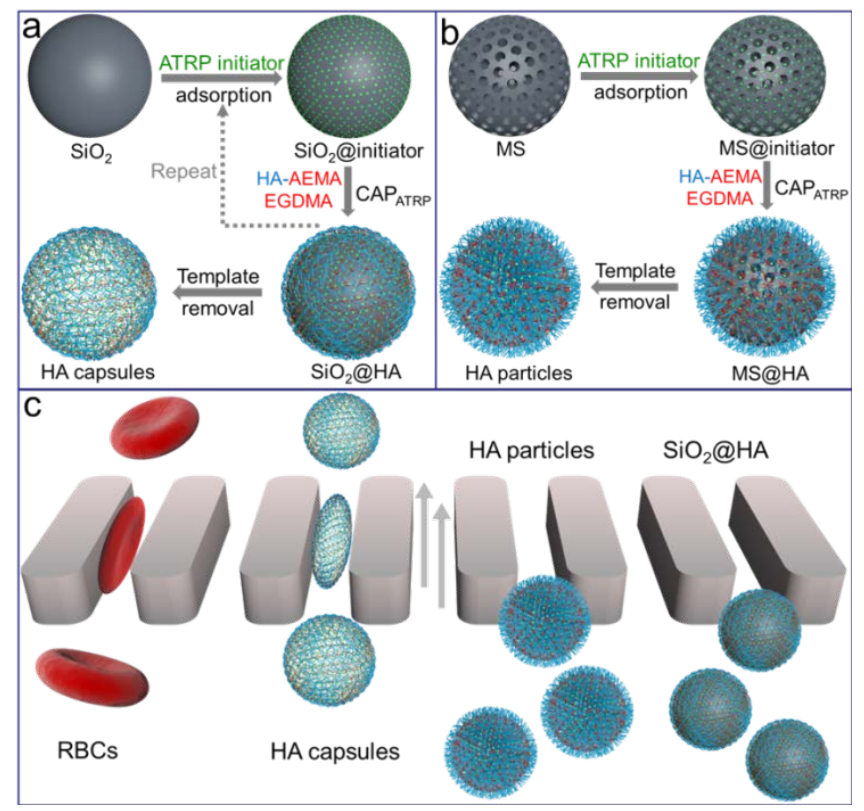

For construction of HA replica particles, one $\mathrm{CAP}_{\mathrm{ATRP}}$ step of HA-AEMA was performed on mesoporous silica (MS) templates (average diameter $\sim 7.2 \mu \mathrm{m}$ ). MS particles were functionalized with ATRP macroinitiator (Scheme
Sib), and subsequently incubated with HA-AEMA and ethylene glycol dimethacrylate (EGDMA) solution for $2 \mathrm{~h}$ prior to $\mathrm{CAP}_{\mathrm{ATRP}}$ by mixing with PMDETA, NaAsc and $\mathrm{CuBr}_{2}$ (Scheme $1 \mathrm{~b}$ ). Various amounts of HA-AEMA (HA to MS weight ratio of $10 \%, 20 \%, 40 \%$, and $80 \%$ ) were used to construct replica particles with different HA densities upon removal of $\mathrm{MS}$ templates, yielding $\mathrm{HA}_{\mathrm{P}_{1}}, \mathrm{HA}_{\mathrm{P}_{2}}$, $\mathrm{HA}_{\mathrm{P}_{3}}$, and $\mathrm{HA}_{\mathrm{P}_{4}}$, respectively. The obtained replica particles were characterized, as shown in Figure 1az-ez and Figure $\mathrm{S}_{3}$. The HA replica particles were well dispersed in aqueous solution and had a size of $\sim 6-8 \mu \mathrm{m}$. However, these particles had a different morphology after airdrying, compared with the HA capsules (Figure 1c1): unlike HA capsules, which showed a fully collapsed structure, HA replica particles maintained more of their spherical shape. This has been observed for other polymer replica particles constructed by surface-initiated ATRP ${ }^{39}$ or through a polymer infiltration-crosslinking method. $4^{40}$ AFM analysis also showed that the height (thickness) of air-dried HA replica particles increased, from $\sim 690 \mathrm{~nm}$ $\left(\mathrm{HA}_{\mathrm{P}_{1}}\right)$ to $\sim 1200 \mathrm{~nm}\left(\mathrm{HA}_{\mathrm{P}_{4}}\right)$, as the initial $\mathrm{HA}$ to $\mathrm{MS}$ weight ratio increased (Figure $S_{2} b$ ), indicating a higher polymer density in HA replica particles prepared using a larger amount of HA-AEMA. Deconvolution microscopy images confirmed the hollow interior of the capsules and a filled interior of the replica particles, demonstrating the difference in internal structure (Figure 1d,e and Figure $\mathrm{S}_{4}$ ).

For particles with the same material composition, the material density and/or amount can be used to tune stiffness. ${ }^{15,41-43}$ In the current study, the amount of HA-AEMA used during $\mathrm{CAP}_{\mathrm{ATRP}}$ was varied and high-resolution nanometer-scale deformation measurements (100 nm deformation) were made using CP-AFM on individual capsules and replica particles in phosphate-buffered saline (PBS) solution. ${ }^{44,45}$ It was found that capsule stiffness increased almost linearly with increasing HA layer number, with the measured stiffness of capsules ranging from $\sim 4.6$ $\left(\mathrm{HA}_{\mathrm{C}_{1}}\right)$ to $13.6 \mathrm{mN} \mathrm{m}^{-1}\left(\mathrm{HA}_{\mathrm{C}_{4}}\right.$, Figure $\left.2 \mathrm{a}\right)$. The stiffness of HA replica particles could also be finely tuned by changing the concentration of HA-AEMA in the CAP $\mathrm{ATRP}_{\text {step, }}$ with values ranging from $\sim 2.4\left(\mathrm{HA}_{\mathrm{P}_{1}}\right)$ to $21.3 \mathrm{mN} \mathrm{m}^{-1}$ $\left(\mathrm{HA}_{\mathrm{P}_{4}}\right.$, Figure $\left.2 \mathrm{~b}\right)$. The observed trend is consistent with a previous report where an increase in crosslinker amount led to an increase in particle stiffness. ${ }^{27}$ Moreover, the stiffness range measured for the replica particles was similar to that for the HA capsules.

The flow-based deformability of the particles was investigated in a microfluidic blood capillary model (Figure 3 ). $\mathrm{HA}_{\mathrm{C}_{3}}$ and $\mathrm{HA}_{\mathrm{P}_{3}}$ had similar nanoscale stiffness (11.1 and 11.4 $\mathrm{mN} \mathrm{m} \mathrm{m}^{-1}$, respectively) and were therefore compared using a recently introduced microfluidic blood capillary model. $^{27}$ This model was designed using physiologically relevant dimensions and pressure drops across capillaries. The capsules and replica particles were injected from a high pressure inlet and only buffer was injected from a low pressure inlet. The four-point device design facilitates the establishment of well-controlled physiologically relevant differential pressures and pressure drops across the 
capillaries, as each inlet can be tuned independently (Figure 3 a). The $\mathrm{HA}_{\mathrm{C}_{3}}$ capsules could deform and passed
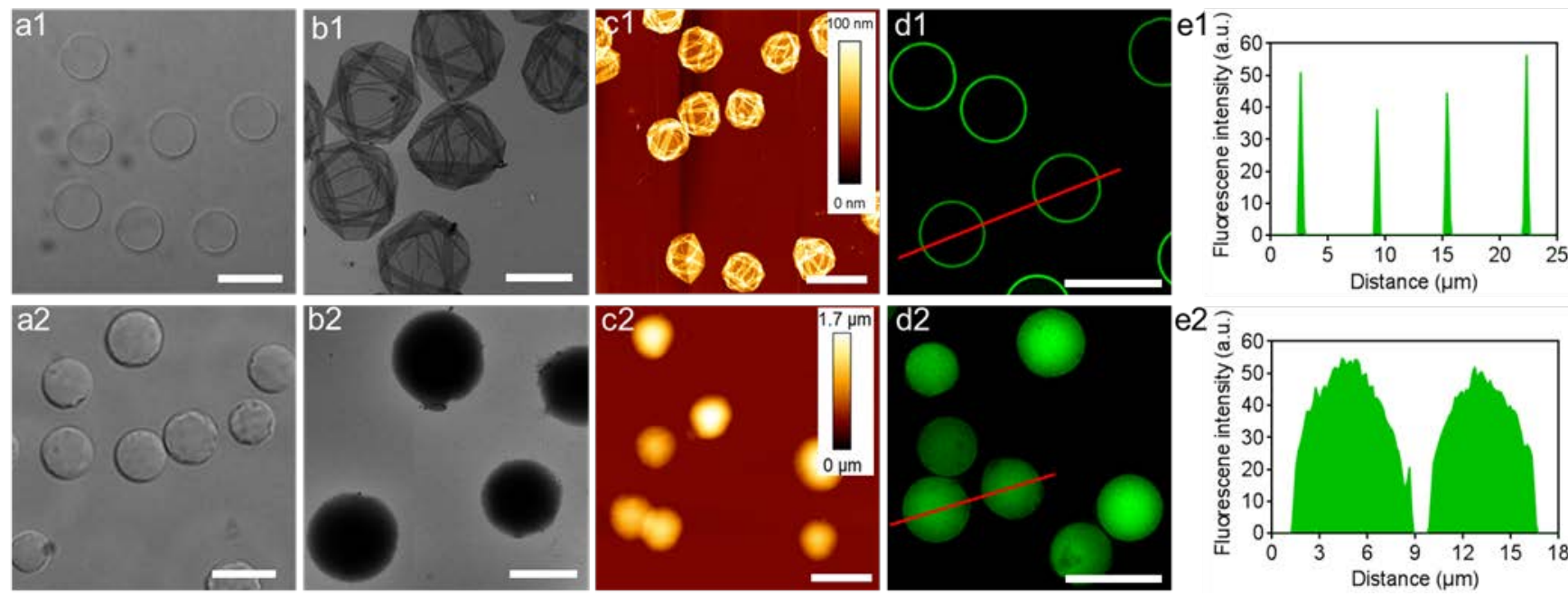

Figure 1. Structural characterization of $\mathrm{HA}_{\mathrm{C}_{3}}$ capsules (a1-e1) and $\mathrm{HA}_{\mathrm{P}_{3}}$ replica particles (a2-e2). (a) DIC microscopy, (b) TEM, (c) AFM, and (d) fluorescence deconvolution microscopy (single z-plane) of $\mathrm{HA}_{\mathrm{C}_{3}}$ capsules and $\mathrm{HA}_{\mathrm{P}_{3}}$ replica particles, respectively. (e) The fluorescence intensity profiles of the red line marked in $d_{1}$ and $d_{2}$, respectively. a1, a2, $d_{1}$ and $d_{2}$ are capsules/particles in solution. b1, b2, c1 and c2 are capsules/particles in the air-dried state. Scale bars are $10 \mu \mathrm{m}$ in a, c, and d, and 5 $\mu \mathrm{m}$ in $\mathrm{b}$.
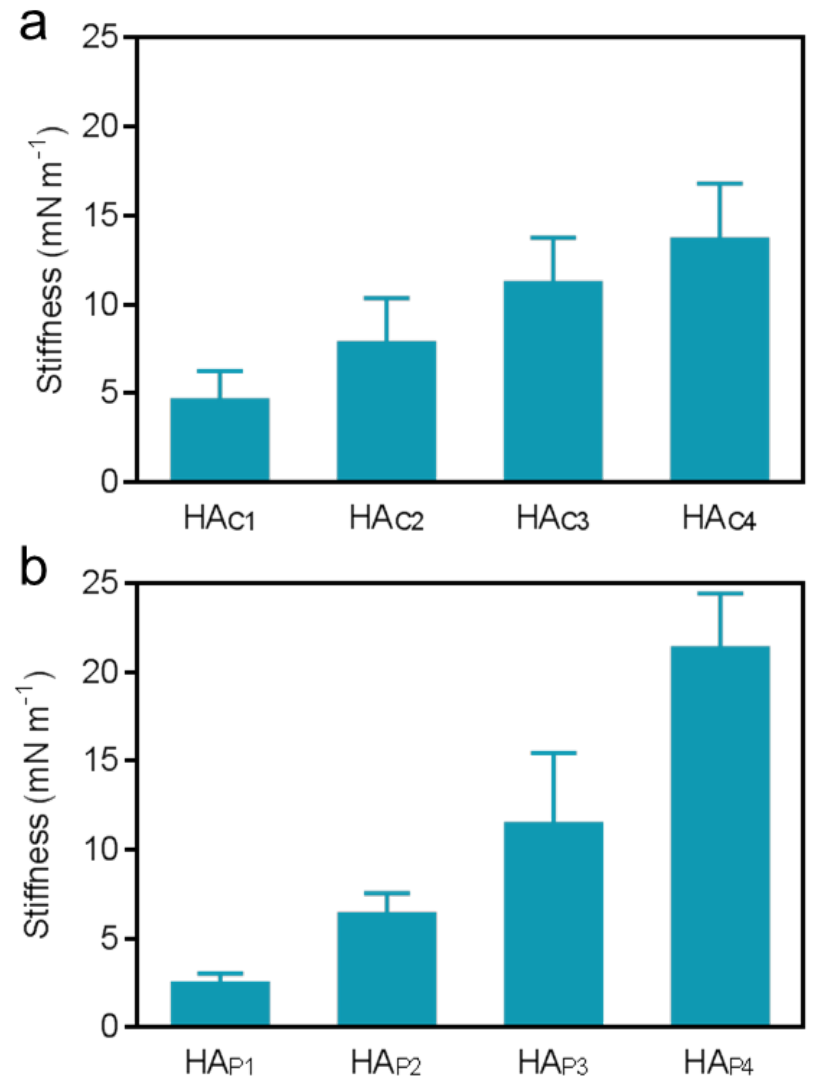

Figure 2. Stiffness of (a) HA capsules with different number of HA layers, and (b) HA replica particles prepared using different HA to MS weight ratios, as determined by CP-AFM analysis. through the capillaries (Figure $3 \mathrm{~b}$ ) with no visibly damaged capsules seen in either of the outlets, thus indicating that the capsules could pass through the capillaries via reversible elastic deformation (Figure $3 \mathrm{c}$ ). However, a different behavior was observed for the $\mathrm{HA}_{\mathrm{P}_{3}}$ replica particles, as they had difficulty passing through the capillaries, especially at lower pressure differentials.

To quantify the differences found in the flow-based deformability behavior of the different particles, particle trajectories in the device were analyzed, and a ratio of the number of particles that passed through the capillaries to the number of particles that stayed on the sample side was calculated (Figure 4). Particles that can easily pass through will have a high ratio while particles that do not pass through will have a ratio of zero. Each measurement was performed in triplicate with more than 100 trajectories analyzed for each replicate. In total, over 10 ooo particle trajectories were analyzed. The controls behaved as expected, with RBCs easily passing through the capillaries and the ratio increasing with increasing pressure drop while none of the $\mathrm{SiO}_{2} @ \mathrm{HA}$ particles (i.e., with core remaining) could pass through, resulting in a ratio of zero, even at higher pressure drops. The capsules $\left(\mathrm{HA}_{\mathrm{C}_{1}}-\mathrm{HA}_{\mathrm{C}_{4}}\right)$ could all pass through the capillaries with relative ease and exhibited deformation-based trajectories in the microfluidic blood capillary similar to the RBCs. However, the replica particles $\left(\mathrm{HA}_{\mathrm{P}_{1}}-\mathrm{HA}_{\mathrm{P}_{4}}\right)$ had difficulty passing through the capillaries, even at higher pressure drops. Even when comparing the capsule with the highest nanoscale stiffness $\left(\mathrm{HA}_{\mathrm{C}_{4}}, 13.6 \mathrm{mN} \mathrm{m}^{-1}\right)$ to the replica particle with the lowest nanoscale stiffness $\left(\mathrm{HA}_{\mathrm{P}_{1}}, 2.4 \mathrm{mN} \mathrm{m}^{-1}\right)$, it was observed that the capsules had a significantly higher ratio, despite the fact that the capsules were almost 6fold higher in nanoscale stiffness. As the main difference 
between the two particle types is their internal structure, where both particle types were made of the same materials and engineered to have the same stiffness at the nanoscale, this demonstrates the importance of particle structure on flow-based deformability in the microfluidic
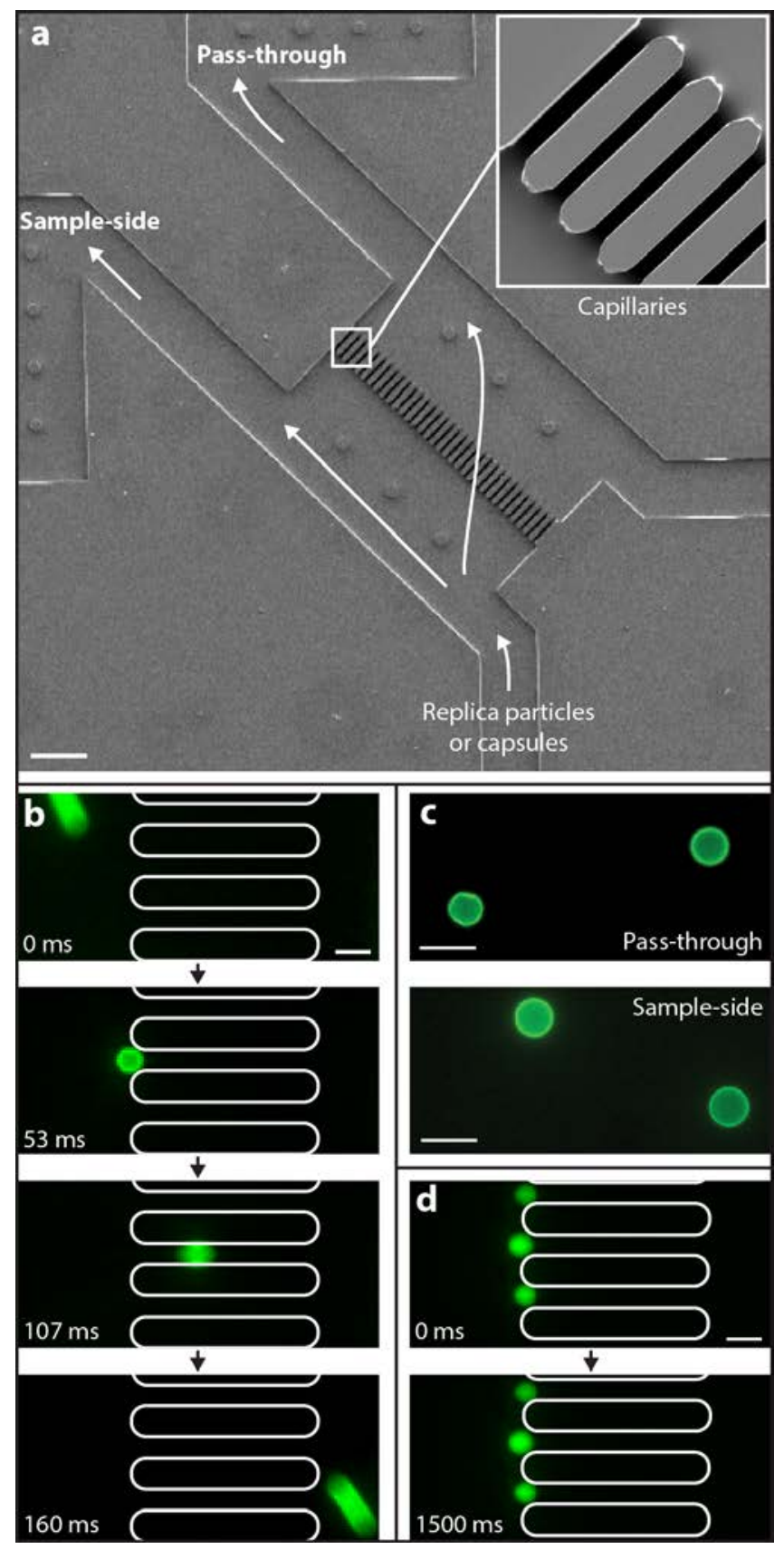

Figure 3. (a) Illustration of available flow paths for HA capsules and replica particles in the microfluidic blood capillary model, overlaid on a SEM image of the PDMS microfluidic device. (b) Time-lapse fluorescence microscopy images of a $\mathrm{HA}_{\mathrm{C}_{3}}$ capsule passing through a capillary. (c) Fluorescence microscopy image of capsules at the outlets of the device after passing through capillaries (pass-through) or staying on the same side (sample-side). Note that the capsules were not visibly damaged. (d) Time-lapse fluorescence microscopy images of $\mathrm{HA}_{\mathrm{P}_{3}}$ replica particles at the entrance of capillaries at lower capillary pressure drops. The pressure drop across the capillaries is $\sim 6 \mathrm{mbar}$ in $\mathrm{b}$ and $\mathrm{d}$. The non-spherical ("drawn out") shape of the capsules observed in some of the time-lapse frames is due to the acquisition rate of the camera. Spherical capsules are again observed when the capsules are no longer in motion (as seen in (c)). Scale bars are $100 \mu \mathrm{m}$ in $\mathrm{a}$, and $10 \mu \mathrm{m}$ in $\mathrm{b}-\mathrm{d}$.

blood capillary model. These results also show the importance of investigating stiffness at different length scales, both at the nanoscale (e.g., using CP-AFM) and at the microscale (e.g., using microfluidic models), to obtain a more complete understanding of the deformability of soft microparticles.

In summary, HA replica particles and HA capsules were nanoengineered through $\mathrm{CAP}_{\mathrm{ATRP}}$. Both particle types were well dispersed in aqueous solution and were of similar size to each other and to human RBCs. The nanoscale stiffness of both particle types was investigated using $\mathrm{CP}$ AFM and it was demonstrated that both replica particles and capsules could be engineered to have similar nanoscale stiffness, with capsule stiffness ranging from 4.6 to $13.6 \mathrm{mN} \mathrm{m}^{-1}$ and replica particle stiffness from 2.4 to $21.3 \mathrm{mN} \mathrm{m}^{-1}$. A microfluidic blood capillary model was then used to investigate the behavior of both particle types in a physiologically relevant flow environment. It was found that the flow-based deformability behavior and the ability to pass through the capillaries for capsules were similar to those of $\mathrm{RBCs}$, while replica particles could not easily pass through the capillaries, even at higher capillary pressure drops. These results highlight how flow-based deformability measurements can complement nanoscale stiffness measurements and demonstrate the impact of particle structure on the overall deformability behavior of particles, thus underlining particle structure as an important parameter that, together with particle stiffness, has the potential for fine-tuning particle behavior in flow-based environments, both in vitro and in vivo. These results can therefore facilitate the rational design of particle systems with improved ability to negotiate biological barriers at multiple length scales, which is important for advancing the use of engineered particles in biomedical applications such as imaging, diagnostics, and drug delivery.

\section{ASSOCIATED CONTENT}

Supporting Information. Full experimental details, supporting scheme and supporting figures. This material is available free of charge via the Internet at http://pubs.acs.org.

\section{AUTHOR INFORMATION}

\section{Corresponding Author}

*Email: gregghq@unimelb.edu.au (G.G.Q.)

* Email: fcaruso@unimelb.edu.au. (F.C.)

\section{Author Contributions}

The manuscript was written through contributions of all authors.

¥These authors contributed equally. 


\section{Notes}

The authors declare no competing financial interest.

\section{ACKNOWLEDGMENT}

This research was conducted and funded by the Australian Research Council (ARC) Centre of Excellence in Convergent

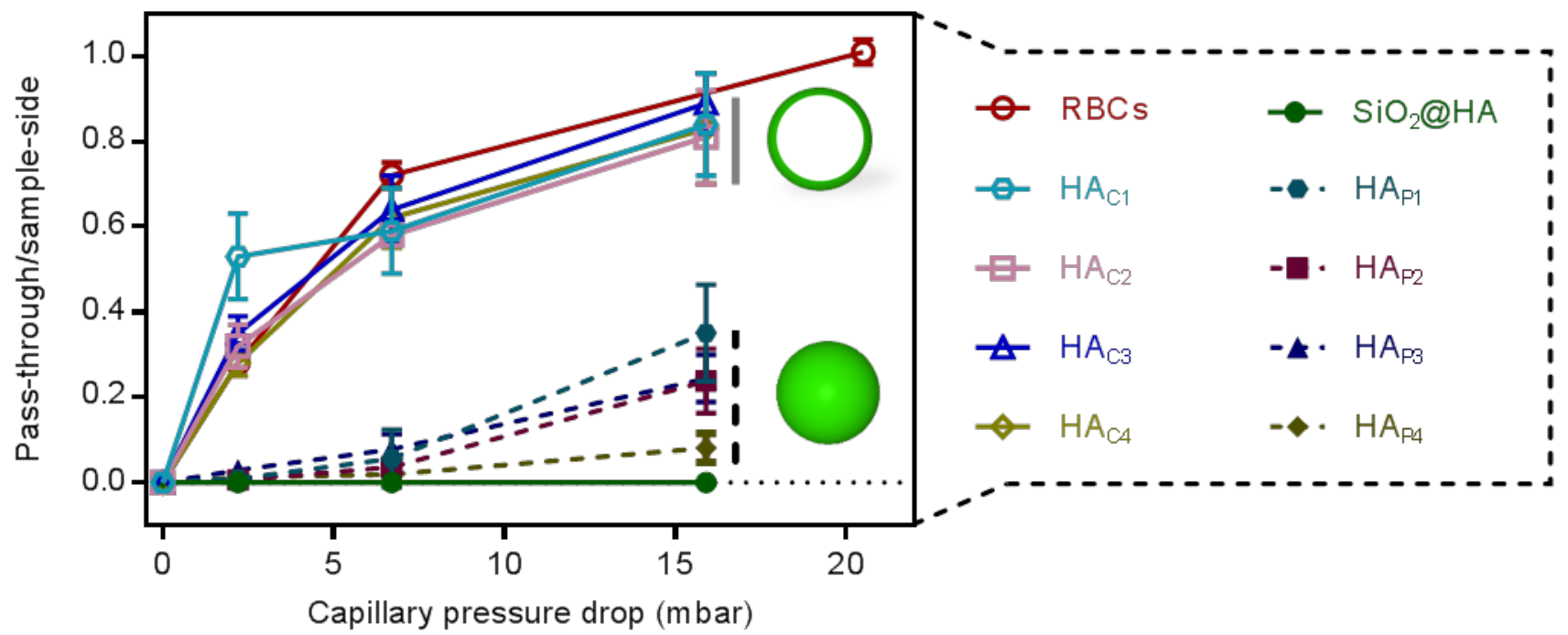

Figure 4. Particle trajectory analysis of HA capsules and replica particles with varying stiffness, SiO $\mathrm{2}_{2} \mathrm{HA}$ and RBCs were used as controls. Number of capsules or replica particles that passed through the capillaries was divided by the number that went to the outlet on the sample side. Capsule data points are indicated by a hollow green circle and replica particle data points are indicated by a solid green sphere. Mean \pm standard deviation, $n=3$.

Bio-Nano Science and Technology (CE140100036). This work was also supported by the ARC under the Australian Laureate Fellowship (FL120100030, F.C.), Future Fellowship (FT110100411, G.G.Q.), Discovery Project (DP1094147 and DP130101846, F.C. and G.G.Q.), and Super Science Fellowship (FS110200025, F.C. and G.G.Q.) schemes, as well as the Australian Government through an Australian Postgraduate Award (M.B.). We acknowledge Martin P. van Koeverden for providing the ATRP macroinitiator, and Junling Guo, Katelyn T. Gause, and Dr. Biao Kong for helpful discussions. This work was performed in part at the Materials Characterisation and Fabrication Platform (MCFP) at The University of Melbourne and the Victorian Node of the Australian National Fabrication Facility (ANFF).

\section{REFERENCES}

(1) De Koker, S.; Hoogenboom, R.; De Geest, B. G. Chem. Soc. Rev. 2012, 41, 2867-2884.

(2) Tanner, P.; Baumann, P.; Enea, R.; Onaca, O.; Palivan, C.; Meier, W. Acc. Chem. Res. 2011, 44, 1039-1049.

(3) Gokmen, M. T.; Du Prez, F. E. Prog. Polym. Sci. 2012, $37,365-405$.

(4) Yan, Y.; Björnmalm, M.; Caruso, F. ACS Nano 2013, 7, 9512-9517.

(5) Nicolas, J.; Mura, S.; Brambilla, D.; Mackiewicz, N.; Couvreur, P. Chem. Soc. Rev. 2013, 42, 1147-1235.

(6) Ernsting, M. J.; Murakami, M.; Roy, A.; Li, S. D. J. Control. Release 2013, 172, 782-794.

(7) Chauhan, V. P.; Jain, R. K. Nat. Mater. 2013, 12, 958962.
(8) Yan, Y.; Björnmalm, M.; Caruso, F. Chem. Mater. 2014, 26, 452-46o.

(9) Nel, A. E.; Madler, L.; Velegol, D.; Xia, T.; Hoek, E. M. V.; Somasundaran, P.; Klaessig, F.; Castranova, V.; Thompson, M. Nat. Mater. 2009, 8, 543-557.

(10) Zhu, M.; Nie, G.; Meng, H.; Xia, T.; Nel, A.; Zhao, Y. Acc. Chem. Res. 2013, 46, 622-631.

(11) Albanese, A.; Tang, P. S.; Chan, W. C. W. Annu. Rev. Biomed. Eng. 2012, 14, 1-16.

(12) Petros, R. A.; DeSimone, J. M. Nat. Rev. Drug Discov. 2010, 9, 615-627.

(13) Sun, J. S.; Zhang, L.; Wang, J. L.; Feng, Q.; Liu, D. B.; Yin, Q. F.; Xu, D. Y.; Wei, Y. J.; Ding, B. Q.; Shi, X. H.; Jiang, X. Y. Adv. Mater. 2015, 27, 1402-1407.

(14) Sun, H.; Wong, E. H. H.; Yan, Y.; Cui, J.; Dai, Q.; Guo, J.; Qiao, G. G.; Caruso, F. Chem. Sci. 2015, 6, 3505-3514.

(15) Hartmann, R.; Weidenbach, M.; Neubauer, M.; Fery, A.; Parak, W. J. Angew. Chem. Int. Ed. 2015, 54, 1365-1368.

(16) Banquy, X.; Suarez, F.; Argaw, A.; Rabanel, J. M.; Grutter, P.; Bouchard, J. F.; Hildgen, P.; Giasson, S. Soft Matter 2oo9, 5, 3984-3991.

(17) Best, J. P.; Yan, Y.; Caruso, F. Adv. Healthcare Mater. 2012, $1,35-47$.

(18) Skalak, R.; Branemar, P. I. Science 1969, 164, 717-719.

(19) Mohandas, N.; Gallagher, P. G. Blood 2oo8, 112, 39393948.

(20) Björnmalm, M.; Yan, Y.; Caruso, F. J. Control. Release 2014, 190, 139-149.

(21) Doshi, N.; Zahr, A. S.; Bhaskar, S.; Lahann, J.; Mitragotri, S. Proc. Natl. Acad. Sci. USA 2009, 106, 21495-21499.

(22) Haghgooie, R.; Toner, M.; Doyle, P. S. Macromol. Rapid Comm. 2010, 31, 128-134. 
(23) Hayashi, K.; Ono, K.; Suzuki, H.; Sawada, M.; Moriya, M.; Sakamoto, W.; Yogo, T. Small 2010, 6, 2384-2391.

(24) She, S.; Xu, C.; Yin, X.; Tong, W.; Gao, C. Langmuir 2012, 28, 5010-5016.

(25) Chen, K.; Merkel, T. J.; Pandya, A.; Napier, M. E.; Luft, J. C.; Daniel, W.; Sheiko, S.; DeSimone, J. M. Biomacromolecules 2012, 13, 2748-2759.

(26) She, S. P.; Li, Q. Q.; Shan, B. W.; Tong, W. J.; Gao, C. Y. Adv. Mater. 2013, 25, 5814-5818.

(27) Cui, J.; Björnmalm, M.; Liang, K.; Xu, C.; Best, J. P.; Zhang, X.; Caruso, F. Adv. Mater. 2014, 26, 7295-7299.

(28) Merkel, T. J.; Jones, S. W.; Herlihy, K. P.; Kersey, F. R.; Shields, A. R.; Napier, M.; Luft, J. C.; Wu, H.; Zamboni, W. C.; Wang, A. Z.; Bear, J. E.; DeSimone, J. M. Proc. Natl. Acad. Sci. U.S.A. 2011, 108, 586-591.

(29) Zhang, L.; Cao, Z.; Li, Y.; Ella-Menye, J.-R.; Bai, T.; Jiang, S. ACS Nano 2012, 6, 6681-6686.

(30) Anselmo, A. C.; Zhang, M.; Kumar, S.; Vogus, D. R.; Menegatti, S.; Helgeson, M. E.; Mitragotri, S. ACS Nano 2015, 9, 3169-3177.

(31) Goh, T. K.; Guntari, S. N.; Ochs, C. J.; Blencowe, A.; Mertz, D.; Connal, L. A.; Such, G. K.; Qiao, G. G.; Caruso, F. Small 2011, 7, 2863-2867.

(32) Mertz, D.; Ochs, C. J.; Zhu, Z.; Lee, L.; Guntari, S. N.; Such, G. K.; Goh, T. K.; Connal, L. A.; Blencowe, A.; Qiao, G. G.; Caruso, F. Chem. Commun. 2011, 47, 12601-12603.

(33) Wong, E. H. H.; Guntari, S. N.; Blencowe, A.; van Koeverden, M. P.; Caruso, F.; Qiao, G. G. ACS Macro Lett. 2012, 1, 1020-1023.

(34) Fery, A.; Dubreuil, F.; Möhwald, H. New J. Phys. 2004, $6,18$.

(35) Vinogradova, O. I.; Lebedeva, O. V.; Kim, B. S. Annu. Rev. Mater. Res. 2006, 36, 143-178.

(36) Kogan, G.; Soltes, L.; Stern R.; Gemeiner P. Biotechnol. Lett., 2006, 29, 17-25.

(37) Ossipov, D. A. Expert Opin. Drug Delivery, 2010, 7, 681703.

(38) Donath, E.; Sukhorukov, G. B.; Caruso, F.; Davis, S. A.; Möhwald, H. Angew. Chem. Int. Ed. 1998, 37, 2202-2205.

(39) Müllner, M.; Cui, J.; Noi, K. F.; Gunawan, S. T.; Caruso, F. Langmuir 2014, 30, 6286-6293.

(40) Cui, J.; Yan, Y.; Wang, Y.; Caruso, F. Adv. Funct. Mater. 2012, 22, 4718-4723.

(41) Palankar, R.; Pinchasik, B.-E.; Schmidt, S.; De Geest, B. G.; Fery, A.; Möhwald, H.; Skirtach, A. G.; Delcea, M. J. Mater. Chem. B 2013, 1, 1175-1181.

(42) Delcea, M.; Schmidt, S.; Palankar, R.; Fernandes, P. A. L.; Fery, A.; Möhwald, H.; Skirtach, A. G. Small 2010, 6, 28582862.

(43) Cui, J.; De Rose, R.; Best, J. P.; Johnston, A. P. R.; Alcantara, S.; Liang, K.; Such, G. K.; Kent, S. J.; Caruso, F. Adv. Mater. 2013, 25, 3468-3472.

(44) Fery, A.; Weinkamer, R. Polymer 2007, 48, 7221-7235.

(45) Schmidt, S.; Fernandes, P. A. L.; De Geest, B. G.; Delcea, M.; Skirtach, A. G.; Möhwald, H.; Fery, A. Adv. Funct. Mater. 2011, 21, 1411-1418. 
SYNOPSIS TOC (for Table of Contents use only)

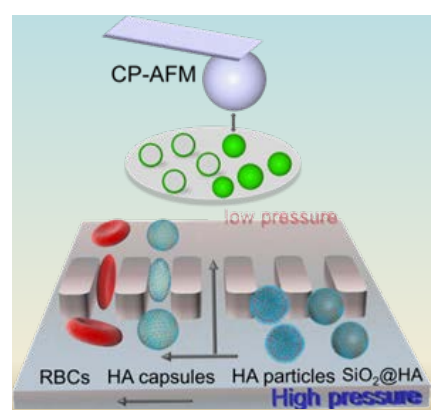




\section{University Library}

\section{- M M N E R VA A gateway to Melbourne's research publications}

Minerva Access is the Institutional Repository of The University of Melbourne

Author/s:

Sun, H;Bjoernmalm, M;Cui, J;Wong, EHH;Dai, Y;Dai, Q;Qiao, GG;Caruso, F

Title:

Structure Governs the Deformability of Polymer Particles in a Microfluidic Blood Capillary Model

Date:

2015-11-01

Citation:

Sun, H., Bjoernmalm, M., Cui, J., Wong, E. H. H., Dai, Y., Dai, Q., Qiao, G. G. \& Caruso, F. (2015). Structure Governs the Deformability of Polymer Particles in a Microfluidic Blood Capillary Model. ACS MACRO LETTERS, 4 (11), pp.1205-1209. https://doi.org/10.1021/ acsmacrolett.5b00591.

Persistent Link:

http://hdl.handle.net/11343/90852 